\title{
Erratum to: Profiling of Fermentative Metabolites in Kimchi: Volatile and Non-volatile Organic Acids
}

Soon-Mi Shim $\cdot$ Ji Yun Kim $\cdot$ Sang Mi Lee $\cdot$ Jin-Byung Park $\cdot$ Sea-Kwan Oh · Young-Suk Kim

Published online: 31 August 2012

(B) Springer-Verlag 2012

Erratum to: J Korean Soc Appl Biol Chem (2012) 55, 463-469

DOI 10.1007/s13765-012-2014-8

The author's affiliation was mistakenly omitted. A complete list of authors and their affiliations follows.

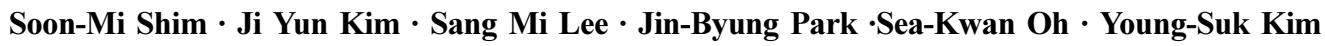

S.-M. Shim · J. Y. Kim • S. M. Lee · J.-B. Park $\cdot$ Y.-S. Kim $(\bowtie)$

Department of Food Science and Technology, Ewha Womans

University, Seoul 120-750, Republic of Korea

E-mail: yskim10@ewha.ac.kr

\section{S.-M. Shim}

Department of Food Science and Technology, Sejong University, Seoul 143-747, Republic of Korea

S.-K. Oh ( $\bowtie)$

Rice Research Division, National Institute of Crop Science, Rural

Development Administration, Suwon 441-857, Republic of Korea

E-mail: ohskwan@korea.kr

The author affiliation is correct in the printed version of the journal.

The online version of the original article can be found under doi:10.1007/s13765-012-2014-8 